\title{
CARTOGRAFÍAS IMAGINARIAS: A PROPÓSITO DE LA OBRA DE RICARDO CADENAS
}

\section{IMAGINARY CARTOGRAPHY: A PROPOS OF RICARDO CADENAS'S ARTISTIC WORK}

\author{
Javier Ariza Pomareta \\ Universidad de Castilla-La Mancha. España \\ Javier.Ariza@uclm.es
}

Este artículo presenta una investigación que explora la obra plástica del reconocido artista Ricardo Cadenas (Sevilla, 1960), incidiendo particularmente en aquellas propuestas creativas y conceptos que de un modo sugerente permiten remitirnos al evocador concepto de cartografía imaginaria. Nuestro estudio ofrece una lectura personal del trabajo y pensamiento de Cadenas. En ella se subraya tanto el valor del dibujo como expresión gráfica y en combinación con otras técnicas y materiales, como la capacidad que su obra nos brinda para establecer nuevas relaciones de carácter abierto y multidisciplinar. Metodológicamente, el estudio se fundamenta en el análisis de obras y textos realizados por el propio autor, entrevistas y conversaciones mantenidas con él, documentación en catálogos, exposiciones y consultas bibliográficas.

Palabras clave: Ricardo Cadenas; dibujo; collage; cartografía imaginaria; imagen.

This paper presents a research that explores the visual work of the renowned artist Ricardo Cadenas (Seville, 1960), focusing particularly on those creative proposals and concepts that allow us to refer to the evocative concept of imaginary cartography in a suggestive way. This study offers a personal approach of the work and thought of Cadenas. It underscores both the value of the drawing as a graphic expression in combination with other techniques and materials, as the ability of his work to establish new open and multidisciplinary relations. Methodologically, the study is based on the analysis of works and texts by the author himself, interviews and discussions with him, catalogues, exhibitions and bibliographic reference documentation.

Keywords: Ricardo Cadenas; drawing; collage; imaginary cartography; image. 


\section{A MODO DE INTRODUCCIÓN}

La obra de Ricardo Cadenas cuenta con un largo recorrido que se inicia en la exploración del dibujo en los albores de su infancia, cuando este se comienza a vislumbrar con la soltura, desparpajo y solvencia de quien observa con agudeza y resuelve certeramente el reto creativo que supone la interpretación gráfica de la realidad. Estos claros indicios de un artista en ciernes no pasaron desapercibidos para quienes tuvieron la oportunidad de observar las condiciones innatas que presentaba para el dibujo aquel joven, permitiéndoles vislumbrar el futuro prometedor que le aguardaba dentro del ámbito de las artes plásticas ${ }^{1}$. Con el transcurso del tiempo, Cadenas cultiva sus aptitudes a través de una práctica artística que se complementa paralelamente con una formación académica universitaria en la Facultad de Bellas Artes de Sevilla. Se enfatiza en su resultado el interés activo y compromiso intelectual por el acto de dibujar como un acto primigenio, esencial y necesario, que constituirá la parte más vital y definitoria en su significación como artista. También lo será, del mismo modo, su reivindicación del dibujo como una herramienta de expresión en combinación con otras técnicas y materiales. Surgen de esta forma obras donde interviene la pintura y, de un modo recurrente, el recurso gráfico del collage. Todo ello representa una instrumentación que esgrime con habilidad y buen hacer para desarrollar y exponer el vasto universo que su mente posee en torno a su particular concepto de imagen pública en relación a sus distintos códigos, iconografías, articulaciones y lenguajes, siendo el cómic, sin ser el único, uno de los más representativos y fecundos.

$\mathrm{Su}$ reconocida experiencia y oficio -como ese creador que hoy continúa siendo- en el ámbito de la pintura y el dibujo le supuso a Ricardo Cadenas su ingreso, en octubre de 1987, en el cuerpo docente de una muy joven Facultad de Bellas Artes de Cuenca ${ }^{2}$, cuya oferta académica había comenzado a desarrollarse con la implantación de la titulación de Licenciado en Bellas Artes en el curso 1986-1987. Su vinculación con esta Facultad se forja de forma permanente a partir del 5 de febrero de 1997, fecha en la que obtiene su nombramiento como Profesor Titular de la Universidad de Castilla-La Mancha. Desde su inicio y hasta el momento actual, continúa desarrollando dos vías fundamentales de toda carrera universitaria: la docente -en las asignaturas de Dibujo presentes en la antigua Licenciatura, en el actual Grado, y en Doctorado y Másteres-; y la investigadora, con participación en distintos proyectos de investigación y el reconocimiento por parte de la Comisión Nacional de Evaluación de la Actividad Investigadora de dos tramos de investigación.

En este punto, consideramos necesario señalar el carácter eminentemente práctico de una actividad investigadora que se centra en el desarrollo de su propia

${ }^{1}$ Entre ellos los artistas Manuel José, Pepe Soto y Fernando Zóbel.

2 Este año 2016 se celebra el $30^{\circ}$ aniversario de esta Facultad de Bellas Artes. 
obra creativa en la que la praxis del dibujo y la pintura se antepone a la teoría. Cadenas expresa que en la tarea artística se ha producido un excesivo acercamiento a la teoría y que en ese acercamiento los artistas "se han alejado de la emoción que se obtiene a partir de una idea y de conocimientos". Esta reflexión la finalizará seguidamente con la siguiente conclusión: "el artista no tiene por qué ser un teórico"’.

Por otra parte, cabría destacar la especial sensibilidad en la relación multidisciplinar que su investigación creativa nos ofrece y que se antoja propia de un viajero cultivado que, sin perder la perspectiva de la contemporaneidad en la que él se ubica, no impide que sus influencias las proporcionen protagonistas y acontecimientos sucedidos en distintas geografías y épocas. Estas influencias multidisciplinares tienen un reflejo continuado en un gran número de sus obras con alusiones gráficas veladas y, en mayor medida, directas, que se presentan como reminiscencias a modo de tributos cuando no homenajes o elegías. Ello nos lleva a vislumbrar una cartografía de la identidad, el pensamiento y la obra de quien habita en su plural imaginario tan rico como variado y yuxtapuesto. Algunas de estas identidades -sus particulares compañeros de ese aventurero viaje a través del tiempo que representa el arte- suelen manifestarse claramente en su obra como cuando en alguna se alude a través de reminiscencias gráficas al ámbito de la literatura de Jorge Luis Borges, por ejemplo, al abordar temas donde intervienen la memoria, el laberinto, el tiempo y la identidad. Igualmente su obra destila de un modo gráfico las numerosas horas de lectura dedicadas a la poesía y narrativa de escritores como el portugués Fernando Pessoa, el filósofo alemán Ernest Jünger, el poeta francés Arthur Rimbaud, la poesía de Miguel Hernández y las novelas de Joseph Conrad ${ }^{4}$, entre otros.

Es necesario destacar aquellas otras identidades relacionadas con el ámbito de las artes plásticas y en cuya obra hace referencia directa al reconocimiento que siente por artistas como, entre otros, su amigo el pintor y arquitecto español Sigfrido Martín Begué -quien también fuera profesor de la Facultad

${ }^{3}$ Entrevista realizada por Marta Carrasco con motivo de la exposición de Ricardo Cadenas en la galería La Caja China, Sevilla, y publicada en $A B C$, jueves 8 de diciembre de 2011, p. 66.

${ }^{4}$ Por su relación con el tema tratado en este artículo, Cadenas nos menciona el valor que poseen para él las novelas de Conrad como, por ejemplo, Lord Jim (1899-1900) y El corazón de las tinieblas. Esta última una obra de aventuras ambientada en el África colonial de finales del siglo XIX y que fue publicada en la revista Blackwood por entregas en 1889 y posteriormente, en 1902, como libro. Consideramos oportuno recordar a un escritor como Sergio Pitol -traductor de autores de lengua inglesa al castellano, entre ellos, Joseph Conrad-, quien pertinentemente afirmaba que "el viaje era la experiencia del mundo visible, la lectura, en cambio, me permitía realizar un viaje interior, cuyo itinerario no se reducía al espacio sino me dejaba circular libremente a través de los tiempos". PITOL, Sergio: El arte de la fuga. México, 2007, p. 169. 
conquense hasta su inesperado fallecimiento en 2010-, Oyvind Fahlström, J. M. Basquiat, Marcel Duchamp, Francis Picabia, Willem de Kooning, Richard Hamilton, Joseph Cornell, Roy Lichtenstein, Jasper Johns o Robert Rauschenberg. Junto a estos referentes cabría destacar aquellos otros artistas de su generación con los que ha compartido exposiciones, amistad y conversaciones en su estudio como representan Pedro G. Romero, Curro González, Gonzalo Puch, Jaime Lorente, Patricio Cabrera, Guillermo Paneque, Federico Guzmán o Javier Buzón, por citar algunos representativos y acotar de modo significativo un listado que sin duda es mucho mayor. También son manifiestas aquellas otras referencias que complementan su particular cartografía de la identidad presente en su obra cuando incluye a protagonistas ubicados en aquellas áreas de interés arraigadas a la cultura de la cual proviene y por las que siente absoluta fascinación como son, por ejemplo, la música flamenca y la tauromaquia. Cabría recordar en este sentido obras y referencias dedicadas a cantaores como Manuel Agujetas, Camarón y Manuel Vega El Carbonerillo, el dibujante y pintor andaluz Andrés Martínez de León, así como las abundantes referencias gráficas sobre toreros como Manolete, Pepe Luis Vázquez o Rafael de Paula, por citar algunos.

Otros habitantes de su memoria que de un modo insistente se manifiestan en esta cartografía -bien sea en sus cuadernos de apuntes, pinturas o dibujos-se encuentran relacionados con ese universo mágico que representa el cine, es el caso de Walt Disney y otros rostros que forman parte de una larga lista de referencias ${ }^{5}$ entre las que podríamos citar a Joan Crawford o Jane Russell, junto a alusiones gráficas más impersonales propias del ámbito de esa otra imagen pública como son las chicas pin-up. A todas ellas se unen aquellos personajes que son propios de ese otro mundo paralelo que es el del cómic con referencias tanto a personajes de ficción -como el Pato Donald, Mickey, Pinocho, Popeye, Betty Boop, Dragon Lady o Tintín-y reales como pueden ser Milton Caniff y Georges Remi Hergé .

${ }^{5}$ Un buen ejemplo lo representa una obra como La Mirada falsa (1996), colmada de referencias a retratos de estrellas cinematográficas.

${ }^{6}$ Cadenas siente fascinación por la exhaustiva metodología de trabajo en la búsqueda, recopilación y documentación que Hergé se impone y exige como condición previa para el dibujo -y a través de él para la narración-de cada uno de los detalles que han de ser dibujados en todos y cada uno de sus álbumes. Una forma de proceder que presenta muchos puntos en común con la del artista sevillano y motivo por el cual le genera tanto interés y fascinación el Museo de Tintín en Lovaina, Bélgica, lugar que ha visitado frecuentemente. La universalidad que transmite el dibujo de Tintín por la documentación previa toma una mayor dimensión tras leer estas palabras de uno de sus máximos expertos como es Benoît Peeters: "Hergé era un ilustrador y un narrador de primer nivel, y uno de los primeros creyentes en el valor artístico de la tira cómica [...] Una de las claves del éxito es que si bien Hergé provenía de un pequeño país y casi no viajaba, su personaje principal encarnaba el movimiento y la curiosidad por el mundo. Y el mundo le devolvió la mano 


\section{EXPLORACIONES DEL TERRITORIO}

Relataba Navarro-Ferré en una de sus novelas que los atlas de islas eran documentos muy apreciados por los coleccionistas "porque sus autores eran unos cartógrafos que al confeccionar las cartas iban descubriendo el mundo. Un mundo soñado y que muchas veces se escapaba de las manos a los exploradores, viajeros y pilotos de la mar" mento inédito cuyo valor no lo es tanto por la hipotética exactitud cartográfica que plasma respecto a lo representado, sino por la consciencia de encontrarse ante un documento que proyecta la vivencia personal de quien lo hizo posible y lo expresó de una forma única basado en su propia experiencia. Un plano cuyo tesoro revelado es, en definitiva, el propio documento.

Cadenas, en su particular exploración del vasto territorio del arte, también ha contribuido con su experiencia a cartografiar de una forma muy personal parte de ese mundo descubierto y soñado por él mismo. Esto lo ha realizado como el propio viajero que ha sido, adentrándose con confianza y seguridad en disciplinas artísticas como el dibujo, la pintura -y la reivindicación del cómic como una categoría equiparable a ellas- cuyas fronteras las observaba permeables e interrelacionadas. La fascinación que le produce el dibujo -como elemento de expresión capaz de esquematizar y sugerir lo inabarcable en un trazo mínimo- encuentra su máximo reflejo en la atracción que le causa, concretamente en este sentido, ese artificio que representa el mapamundi y, también, el crucigrama ${ }^{8}$.

$\mathrm{Su}$ bagaje se manifiesta a través de dos aspectos fundamentales. El primero, el que resulta más visible e identificable, lo desarrolla desde su propia experiencia, emoción y recuerdos finalmente proyectados en una obra plástica en la que abundan referencias y conceptos a una cartografía sugerida a través del dibujo, la pintura y el collage. El segundo aspecto, menos intenso pero no por ello menos importante, nos remite al estudio y análisis teórico del territorio artístico en el que también tiene lugar su propia experiencia creativa. Esto conlleva una implicación personal que se expresa con propiedad en sus textos y escritos principalmente, pero también en sus entrevistas y conversaciones muchas de ellas transcritas en catálogos y abundantes artículos de prensa.

En referencia a este último, señalaremos el interés de un documento como representa el titulado Aproximación a la práctica artística durante los años ochenta, a partir de la obra de cinco artistas de Sevilla. Se trata de la tesis doctoral con la que

generosamente". Cita presente en el artículo que firma Brigid Grauman y publicado el 6 de junio de 2009 en http://www.lainformacion.com/mundo/el-nuevo-museo-herge-una-casapara-la-eternidad-de-tintin_bDy11Uq09kxOaWbn0TAw81/ (Consultado el 25-9-2016).

7 NAVARRO-FERRÉ, José: El viajero de las islas atlánticas. Cuenca, 2004, p. 17.

${ }^{8}$ En 1988 presentó en la galería Carles Taché de Barcelona -en una exposición en la que también participaban Patricio Cabrera y Federico Guzmán- la obra $S / T$ (1988), que contenía referencias gráficas a crucigramas. 
obtuvo el grado de Doctor por el Departamento de Arte de la Facultad de Bellas Artes en la Universidad de Castilla-La Mancha el 16 de febrero de 1994. En ella reivindica, desde la pasión que caracteriza su impulso vital, una investigación teórico-práctica en las bellas artes cuya exhaustividad se aleja de los cánones ortodoxos propios de una perspectiva académica. La sitúa en el contexto histórico de los años ochenta en Sevilla desde la mirada de quien realiza una labor profesional como artista, acercándose al mismo tiempo, a la obra y, sobre todo, a la opinión de algunos -en aquel tiempo- jóvenes artistas de su generación, la mayoría de ellos pintores, con los que compartía un mismo momento histórico. En el documento queda expresado uno de los objetivos de esta investigación como era la intención por definir un territorio personal para la creación. Para ello se sirvió también de una metodología cualitativa que subrayaba el valor de la entrevista. Aquellos artistas entrevistados, y que dotaron de dirección a la particular cartografía artística sevillana expuesta por Cadenas para ese periodo concreto de tiempo, fueron Gonzalo Puch, Curro González, Patricio Cabrera, Guillermo Paneque y Federico Guzmán.

Cabría destacar en este punto el valor de la entrevista como metodología para el revelamiento y descripción del territorio por el que transcurre el arte de Cadenas. Excelente, en este sentido, es la firmada por Juan Bosco Díaz de Urmeneta, bajo el título "El dibujo, un espacio mental", para el catálogo Procesos. El revés de la imagen, realizada con motivo de la exposición de Cadenas en la Fundación Aparejadores de Sevilla celebrada en 2003. Se trata sin duda de una valiosa entrevista que posteriormente será recuperada en una versión reducida y fragmentada para el catálogo de la exposición Escáner subjetivo, realizada en la galería Depósito 14, en Madrid, en 2005.

Cadenas se presenta como un ser cercano, accesible y dispuesto a emprender un ágil pero profundo diálogo que nos revela la riqueza de su apasionada conversación basada en la experiencia acumulada y una reflexión docta ${ }^{9}$. La entrevista periodística a la que siempre se ha prestado con motivo de su actividad creativa nos ofrece jugosos fragmentos y esencias de su pensamiento derivados de la inmediatez y frescura que ofrece la fórmula pregunta-respuesta. Sin embargo, es en textos reposados como El dibujo como un espacio para la fragmentación y lo múltiple (2005) -en nuestra opinión uno de sus textos teóricos más sólidos de cuántos ha escrito- donde queda reflejado su posicionamiento teórico-práctico de un modo contundente y clarificador. Se observa, no obstante, cómo se mantiene de forma coherente a lo largo de todo el tiempo la perseverancia en las convicciones y el denominador común que caracteriza la particular exploración de un territorio artístico a través de la práctica del dibujo y la pintura.

${ }^{9}$ Un aspecto que ha contribuido a un mejor desarrollo de este artículo, ya que hemos podido contar, siempre que se lo hemos solicitado, con su conversación y colaboración. 


\section{HACIA UNA CARTOGRAFÍA IMAGINARIA}

El trabajo de Cadenas se caracteriza principalmente por la reflexión, no exenta de crítica, que le ha merecido la imagen pública y, a través de esta reflexión, su exploración creativa a través de un primer proceso que parte del dibujo y el collage con la intención de provocar otro tipo de emociones. Se trata, por tanto, de un procedimiento reflexivo e intelectual del cual siempre le ha interesado "la posibilidad de exploración mediante la tarea artística, del espacio que hay entre la pintura y la multitud de imágenes que, querámoslo o no, presionan sobre nuestro cerebro"10.

La exploración del espacio se traduce en la obra de Cadenas en el despliegue de una particular representación cartográfica donde tiene lugar el desembarco de su vasta memoria, experiencia y emociones. En ocasiones las imágenes y los trazos se superponen caudalosamente sucediéndose en un recorrido a veces laberíntico, colmado de fragmentos de referencias dispersas cuyo objetivo atiende más a la necesidad de sugerir una posibilidad antes que a señalar una certeza. Se trata, en su opinión, de "el establecimiento de un imaginario visto en términos de simultaneidad no jerárquica, cuya asociación depende en gran medida de una lectura abierta más relacionada con la indagación que la mirada pudiera hacer delante de un mapa, que con el seguimiento más o menos ordenado de una serie de figuras estáticas" 1 . Se propone de este modo una amalgama de imágenes que pueblan el espacio. Estas llegan a alcanzar en abundantes ocasiones una estructura rizomática donde quedan expuestas como la enigmática señalética de un mapa personal.

En este sentido, Cadenas considera las imágenes "más índices que representaciones de objetos, y así más tendentes a señalar direcciones o recorridos diversos. El cuadro, el dibujo, o la obra gráfica es, más que una invitación a la contemplación, un estímulo a la indagación de la mirada"12. El conjunto de estas imágenes fragmentadas de orígenes contrapuestos desgranan una elevada poesía gráfica debido a su poderosa capacidad evocadora.

Borges expresó esta idea de un modo tan hermoso y definitivo que su mención, aun reiterada, nos resulta irrenunciable e imprescindible por lo adecuada y directa relación que ofrece ante la obra desarrollada por Cadenas. Nos referimos al maravilloso segundo párrafo del epílogo de la recopilación de la obra de Borges llevada a cabo en 1960 y recogida bajo el título El hacedor que dice así: "Un hombre se propone la tarea de dibujar el mundo. A lo largo de los años puebla

${ }^{10}$ CADENAS, Ricardo: "El dibujo como un espacio para la fragmentación y lo múltiple", en Explorando el Laberinto. Creación e investigación en torno a la gráfica digital a comienzos del siglo 21. Cuenca, 2005, p. 59. La publicación aglutina las diferentes investigaciones realizadas por los miembros del grupo de investigación formado en 2002 en el entorno de la gráfica digital y perteneciente a la Facultad de Bellas Artes de Cuenca.

${ }^{11}$ Ibidem, p. 60.

12 Ibid. 
un espacio con imágenes de provincias, de reinos, de montañas, de bahías, de naves, de islas, de peces, de habitaciones, de instrumentos, de astros, de caballos y de personas. Poco antes de morir, descubre que ese paciente laberinto de líneas traza la imagen de su cara"13.

La extraordinaria poética que nos trasmite este breve texto, que nos remite a la perseverancia creadora de una búsqueda incesante de lo externo -cuando el resultado de esa labor indagadora del entorno termina por reflejarnos a nosotros mismos al final de los tiempos como un espejo burlón-, nos lleva a considerar que, probablemente, todo acto de búsqueda del exterior encuentra su correspondiente reflejo con un revelamiento del propio interior. Algunas obras parecen reflejar este concepto con mayor claridad. Es el caso, por ejemplo, de una obra como $S / T$ (Línea de cambio de fecha) de 1991, en la que sobre una elipse que remite al globo terráqueo se dibujan una secuencia de perfiles de una cara que paulatinamente tiende a convertirse en los continentes de esa Tierra imaginaria (Figura 1). Con una poética formal ligeramente distinta se encuentra concebida la obra Sin Título (Autorretrato) de 1998. Una amalgama yuxtapuesta de líneas entre la que destaca el dibujo frontal de su autorretrato en la parte central y, en cada uno de los extremos del papel, dos cráneos que lo intersectan. Nos resulta inevitable en este punto comentar la similitud que parecen presentar estos dos perfiles de cráneos con la proyección estereográfica de todo el globo representada en dos hemisferios que, tal como observa Lino Cabezas, "aparece por vez primera en un mapamundi de 1542, del cartógrafo Jean Rotz, de la escuela francesa de Dieppe"14.

Quizá esta sea una de las razones por las cuales en esa cartografía de la identidad que proyecta Cadenas advertimos que en su obra el sujeto central al que hace referencia a lo largo del tiempo, si bien de un modo intermitente, es él mismo. Su autorretrato, por ejemplo, constituye un leitmotiv que surge frecuentemente en sus obras bien como línea yuxtapuesta, bien como dibujo descriptivo, bien como silueta. Esta se fusiona con las imágenes que pueblan la superficie para formar parte integral de ella remitiéndonos de este modo a una presencia -no exenta en ocasiones de una sugerida ausencia- que se expresa y se desarrolla como una realidad fragmentada y múltiple expandida en un universo omnidireccional. Lejos de interpretar la presencia de su identidad como un acto de autocomplacencia, esta la observamos como un signo de confirmación de su implicación en el acto creativo que lleva a cabo y al conocimiento que posee respecto a lo representado. Resultaría por tanto una aberración el obviar intencionadamente su propio yo

${ }^{13}$ BORGES, Jorge Luis: Obras completas I. Barcelona, 2005, p. 854. Este párrafo sirve como cita introductoria del catálogo El arte como juego, realizado con motivo de la exposición de la obra de Ricardo Cadenas celebrada en la Fundación Antonio Pérez, Cuenca, en 2003.

${ }^{14}$ CABEZAS GELABERT, Lino: "Cartografía, mapas y planos”, en Dibujo y territorio. Cartografia, topografia, convenciones gráficas e imagen digital. Madrid, 2015, p. 112. 
cuando existe una clara intencionalidad de desplegar una cartografía propia que intenta proyectar su emoción y vivencia personal. La intrincada complejidad con la que se desenvuelve esta cartografía que son sus autorretratos se explica por sí misma cuando se contempla la yuxtaposición de numerosas capas e imágenes a modo de sustratos que convergen en la superficie tal y como nos advierte Horacio Fernández: "están compuestos por sucesivas capas de mapas, señales, muñecos, esquemas, máquinas, calaveras y otras muchas osamentas o perfiles de las variadas fuentes que el artista reconoce como propias"15.

Algunas obras como Perfil y Perfil (I), ambas de 1993, suponen claros ejemplos de lo expresado anteriormente. En la primera observamos una imagen que, como una sucesión de diferentes estratos, ofrece una cartografía que combina -de izquierda a derecha- un mapa, cráneos y su propio perfil dibujado a línea (Figura 2). En la segunda, una versión de la anterior, los estratos gráficos están formados por un cúmulo de cartas aéreas fotocopiadas en papel vegetal entre cuya maraña de líneas y textos se percibe el perfil trazado a mano de un cráneo y el perfil de su propio rostro (Figura 3).

Sin embargo, esta proyección personal no solo se encuentra expresada de un modo explícito, como ya hemos señalado, a través de los autorretratos que muestran su cara, también se encuentra en aquellas obras en las que su mano aparece plasmada realizando el acto creativo ${ }^{16}$. Ello nos parece indicar que su intención no pretende tanto representar el dibujo como un fin en sí mismo, sino exponer el propio acto de dibujar como medio de conocimiento y actitud metodológica ante la vida. Él lo ha expresado de este modo: "Más que la pintura u otra operación técnica, a mí lo que me gusta en el arte es el papel y el lápiz. En nuestra cultura mediterránea el dibujo durante siglos no fue suficientemente valorado porque lo que importaba no era el proceso sino el resultado" 17 .

Cabría reseñar la capacidad para discernir el componente genuino que enriquece la experiencia, pudiendo ser, en el caso de un viajero aventurero, no tanto la llegada al destino como las vicisitudes del propio viaje. Esa es la lección que nos ofrece Kavafis en su poema Ítaca y el mensaje que a modo de paráfrasis está presente en la filosofía creadora de Cadenas, al enfatizar este como eje central la exhibición de los entresijos de su proceso creativo. Por esta razón sus exposiciones

${ }^{15}$ FERNÁNDEZ, Horacio: "Ricardo Cadenas", en El arte como juego. Cuenca, 2003, p. 19.

${ }_{16}$ Algunas obras que reflejan esta característica son, entre otras, Sin Título (El juego del dibujo), Sin Título (El juego del dibujo I) y Sin Título (El juego del dibujo II), todas ellas de 2002; Caza Sutil (2006); y Sin Título (2007).

${ }^{17}$ Ver en la entrevista que le realiza Charo Ramos publicada en edición electrónica en Diario de Sevilla el 21 de diciembre de 2014. Acceso al documento en http://www.diariodesevilla.es/article/ocio/1925989/ricardo/cadenas/rastreador/imagenes.html (Consultado el 18-9-2016). 
suelen ir acompañadas de vitrinas colmadas de recortes de imágenes de múltiple procedencia ${ }^{18}$. Son su particular cuaderno de bitácora de un viaje sin límite. También es habitual el despliegue de este abundante material iconográfico directamente en las paredes de la sala de exposiciones. El pintor Jaime Lorente ha llegado a definir este rasgo de la obra de Cadenas con un término tan acertado como es el de enciclopedismo. En relación a él resulta muy interesante esta propuesta, una de las muchas posibles como bien nos advertirá, que nos plantea Lorente para acercarse y apreciar la obra de Cadenas: "podría ser la de situarse azarosamente en un punto cualquiera de sus dibujos o pinturas y dejarse llevar a partir de ese momento por las muchas relaciones que se despliegan ante nosotros. Silenciosamente se irán extendiendo para formar una espiral cuyo mecanismo, previamente urdido, termina por engullirnos"19.

\section{TOPOGRAFÍAS DE LA IMAGEN}

En algunas obras de Cadenas se observa la posibilidad de interpretar la identidad del sujeto como la transmutación de una particular topografía intrincada y compleja. Esto se encuentra expresado en algunos de sus autorretratos como Autorretrato como un personaje y Autorretrato como máquina, ambas fechadas en 1997. En otras obras, en cambio, esta transmutación la encontramos reflejada en un juego visual que relaciona sujeto-paisaje a través de la interpretación de la línea de contorno de una determinada orografía. Un claro ejemplo lo representa $E l$ diablo (1996), un dibujo a modo de díptico donde, en la mitad izquierda, destaca el perfil de la cara de Duchamp sobre un fondo negro mientras que, en la mitad derecha, una caprichosa arquitectura pétrea presenta un hueco abierto que sugiere el perfil de un rostro análogo $\mathrm{o}^{20}$. Esa misma dirección topográfica -el paisaje trazando un sinuoso contorno en el horizonte que se transmuta en identidad-se observa en la serie sobre el torero Manolete que trabaja, también en 1996, como una particular elegía ${ }^{21}$. Cabría hacer referencia a otra obra del mismo año, Mapa (1996), interpretado como un díptico que ofrece en una de sus mitades el dibujo

${ }^{18}$ Este formato fue el que presentó en su última exposición titulada Material de Trabajo, realizada en la Fundación Antonio Pérez en Cuenca entre el 19 de noviembre de 2015 y el 31 de enero de 2016, y descrita como una selección de dibujos, collages y fragmentos que forman parte del proceso previo al desarrollo de los trabajos posteriores.

${ }^{19}$ LORENTE, Jaime: "Maneras en la obra de Ricardo Cadenas", en Swing Drawings Serenade. Sevilla, 2010, p. 76.

${ }^{20}$ Esta formación rocosa que Cadenas dibuja representa el mirador natural conocido popularmente como el Ventano del Diablo, en Cuenca, que ofrece unas impresionantes vistas a la hoz del Júcar y a la serranía conquense.

${ }^{21}$ Cadenas nos relata en una entrevista que el origen de estas obras se encuentran en un recuerdo de niñez de cuando viajaban en coche por una carretera sinuosa de Antequera 
de un perfil antropomórfico a línea que en la otra mitad se convierte en una pintura que representa esa identidad traducida como una suerte de isla rodeada por el mar. Se trata de la interpretación de un lugar de la costa asturiana cuya leyenda cuenta que esa formación de la roca azarosa representa el perfil del rostro de Cristo. Mención especial merece las obras El faraón dormido I y El faraón dormido II, ambas de 1996, en las cuales el contorno de una montaña de Marbella muestra un sutil perfil que inspira la de una figura yacente ${ }^{22}$. Se sugiere en cualquier caso un ejercicio de relectura, también de indagación e interpretación. De algún modo se establecen en todas estas obras una intencionalidad de observar la orografía como un soporte de naturaleza básica. Esta nos remite a lo primigenio, la tierra, cuyos distintos contornos y estratos albergan contenidos latentes aún por descubrir. Cadenas parece advertirnos de que las señales que nos revelan indicios para el hallazgo de estos son muy sutiles y bien pudieran pasar desapercibidas salvo para el ojo del atento observador ${ }^{23}$. A partir del descubrimiento de alguna de estas primeras señales, el espectador pasa a convertirse en un agente activo ya que podrá profundizar y recuperar sucesivas señales, signos y acontecimientos que le den pie a construir, si así lo desea, su propio relato. El valor alegórico que expresa esa visión telúrica del arte se encontraba conceptualmente reflejado en la exposición Arqueología ${ }^{24}$ que realizó en el espacio sevillano La Caja China en 2014. Con motivo de su obra Cadenas expresó esta metafórica idea: "Vivimos saturados de imágenes, muchas veces brillantísimas, pulidas, digitales o manufacturadas. Por ello me interesaba rescatar los restos de una particular iconografía que permanece oculta entre esa montaña de impactos visuales, rasgar y desentrañar lo que hay detrás de ellas" ${ }^{25}$. Por esta razón, Cadenas presta una especial atención a todo tipo de estímulos, aun en apariencia débiles, ya que, en cambio, son susceptibles de poseer una esencia rica, profunda y fértiil ${ }^{26}$.

y, en un punto concreto, tras un cambio de rasante, aparecía el perfil de una montaña que su padre no dudaba en identificar con la figura yacente del torero.

${ }_{22}$ Estas obras se encuentran documentadas en el catálogo De entre los muertos, realizado con motivo de su exposición en la galería de arte Fausto Velázquez en mayo de 1996.

${ }^{23}$ Señalar en este sentido la inclusión en su obra El faraón dormido II (1996) de la célebre calavera anamórfica presente en el cuadro titulado Jean de Dinteville y Georges de Selve (1533), más conocido como Los embajadores, del pintor Hans Holbein el Joven.

${ }^{24}$ En la entrevista realizada por Marta Carrasco publicada en ABC el lunes 29 de diciembre de 2104, p. 77, Cadenas matiza el empleo del término arqueología con estas palabras: "Un término usado de forma subjetiva, más bien como intentando configurar la idea del artista como rastreador, indagador". http://hemeroteca.abc.es/nav/Navigate.exe/hemeroteca/sevilla/abc.sevilla/2014/12/29/077.html (Consultado el 21-9-2016).

${ }^{25} \mathrm{http} / / /$ www.diariodesevilla.es/article/ocio/1925989/ricardo/cadenas/rastreador/imagenes.html (Consultado el 18-9-2016).

${ }^{26}$ Esta idea queda expresada en la breve introducción que escribe para su libro Caza Sutil, Cuenca, 2006, s. p. Una publicación que recoge resultados de su investigación dentro 


\section{DIAGRAMAS, ESPACIOS Y MEMORIA}

La Real Academia de la Lengua española ofrece dos acepciones para el término diagrama. La primera lo expresa como un dibujo geométrico que sirve para demostrar una definición, resolver un problema o representar de forma gráfica la ley de variación de un fenómeno. Su segunda acepción lo define como un dibujo en el que se muestran las relaciones entre las diferentes partes de un conjunto o sistema. Cadenas utiliza el diagrama como una de las muchas formas posibles que permiten pensar en el dibujo tal y como se extrae de esta afirmación: "una posible es aquella que va elaborando signos de un ideograma complejo, que va persiguiendo determinada caligrafía de las imágenes para construir conjuntos de líneas ágiles, sutiles y quebradizas, como los propios insectos y sus movimientos"27.

La noción de diagrama es muy potente en la obra de Cadenas y se encuentra contemplada desde varias perspectivas. La más evidente se observa en la abundante producción creativa en la que interviene una forma de construcción gráfica como corresponde a la anteriormente descrita en su cita. Es el caso, por ejemplo, de la obra que de forma genérica se podría englobar en el epígrafe Caza Sutil realizada en 2006. Un particular homenaje a la obra de su admirado Ernest Jünger, quien sentía directa afición por el mundo de los insectos -en concreto por las mariposas- y que Cadenas lo advierte como un magnífico universo repleto de vitalidad pero prácticamente silencioso que bien pudiera pasar desapercibido a los ojos de los demás debido, entre otros motivos, a la vertiginosidad con la que se desenvuelven otros acontecimientos en apariencia más notorios y ruidosos que terminan por distraer la atención. Se perciben como un comportamiento existencial el de los insectos y la entomología, a los que Cadenas considera símbolos que guardan relación directa - desde la perspectiva teórica que le procura las lecturas del escritor alemán- con la forma y ciencia en que la que se practica el dibujo.

Un buen número de las obras que firma nuestro autor toman el indeterminado título de Sin Título, en ocasiones acompañado de un subtítulo. Sin embargo, aunque muchas de ellas nos permiten reconocer el desarrollo del concepto de diagrama, son tan solo unas pocas en las cuales el término diagrama aparece explícitamente enunciado como parte del título. Algunas documentadas en diferentes catálogos de exposiciones son, por ejemplo, la obra Ruido-Fluido de líneas. Diagrama de la ciudad (1999). Otro ejemplo lo encontramos en Sin Título

del proyecto realizado por el grupo de investigación de Gráfica Digital de la Universidad de Castilla-La Mancha compuesto por Ricardo Cadenas, Jaime Lorente y Gonzalo Puch, bajo la dirección de Javier Lloret. El libro está compuesto por dos volúmenes. El primero corresponde al ya referido Caza Sutil, de Ricardo Cadenas, y el segundo, Cazador y Perro en tres ciudades, de Jaime Lorente.

${ }^{27}$ Ibidem, s. p. 
(Diagrama del Tiempo), realizada en 2002, una obra de técnica mixta -óleo y lápiz sobre papel- que presenta la particularidad añadida de contener en su superficie el texto de referencia del título como una imagen textual que acompaña al resto de las imágenes que formalizan la obra -un círculo en torno al cual se ubica, una planta, una calavera, otros textos e imágenes cubiertos parcialmente por pintura, y un reloj en una posición central y elevada (Figura 4)-. También encontramos un título semejante en la obra realizada en 2003 y titulada como Sin Título (Diagrama del Tiempo II). Se trata de un óleo sobre cartón que representa el interior de la cabina de un avión que ofrece la percepción de un paisaje urbano en la línea de horizonte vislumbrado a través de las ventanas. Ambas reflexionan sobre algunos aspectos conceptuales comunes característicos en su obra: el tiempo, representado como un reloj y las cartas de navegación aérea, como un mapa cuyo recorrido interviene en la variable percepción que tenemos del mismo debido al empleo de distintos husos horarios en la Tierra.

Por otra parte, cabría tener presente en la obra de Cadenas el tratamiento que recibe un concepto como es el espacio abordado de distintas formas. Entre ellas, las principales son como un espacio para el dibujo, un espacio mental y un espacio para la fragmentación y lo múltiple. Al respecto de las obras de Cadenas, la comisaria Aurora García las define como mapas de la memoria y ha señalado que estos "vienen a ser espacios mentales poblados de seres y cosas donde lo pertinente radica en la trama de relaciones, tanto familiar como insólita, que esos habitantes, percibidos o no, indican" 28 . Un espacio que tiende a mostrarse por otra parte superpoblado y asfixiado de referencias -en palabras de Álvaro Cadenasdonde la memoria juega un papel fundamental "asumiendo todos los referentes, todas las líneas, todos los iconos”29. Algunas obras de Cadenas se remiten al espacio mental aludiendo directamente al cerebro y, en consecuencia, al dibujo como una actividad intelectual. Este aparece representado en obras como El sistema nervioso (1993) y El arte como juego (Díptico) (2001).

Todas estas y otras muchas referencias se encuentran cohabitando en el mismo tiempo y el mismo espacio, apareciendo y desvaneciéndose. Cadenas lo expresaba de este modo: "Rondaba en mi cabeza un sistema de signos intermitentes, aparecían y desaparecían como en los paneles de puntuación que hay en los estadios. Recorrido no lineal, donde se entremezclan las luces, las señales, y el horario de salida o de llegada en los viajes. Las ideas pueden ser líneas y signos que trabajan dentro de un fluido que estalla con sonido en algunos puntos: como un circuito electrónico" ${ }^{30}$. Una obra temprana que refleja esta imagen mental la representa la

${ }^{28}$ GARCÍA, Aurora: "Mapas de la memoria”, en Elegía. Sevilla, 2008, p. 14.

${ }^{29}$ CADENAS, Álvaro: "El proceso artístico como guarida del ruido", en El arte como juego. Cuenca, 2003, p. 39.

30 CADENAS, Ricardo: Ricardo Cadenas, en el catálogo de la exposición realizada en la galería La Máquina Española. Madrid, 1988, s. p. 
obra Memoria electrónica (1988), en la que utiliza pintura industrial sobre madera para representar un esquema electrónico que conduce finalmente a la silueta de un hombre en el centro de la superficie.

El tiempo, como concepto y símbolo, también forma parte de su cartografía imaginaria. Inevitablemente emparentado con la memoria se encuentra simbólicamente representado en numerosas obras de una forma sutil aunque también de forma muy evidente como, por ejemplo, cuando inserta relojes, calaveras o distintas osamentas. Todas estas referencias descritas suponen una codificación gráfica donde la memoria expone sus referencias y construye una ficción basada en recortes, disecciones y fragmentos de una realidad alterada por el tiempo y la interpretación de los acontecimientos. Sobre el proceso de construcción de la memoria Leo de Blas ha señalado que "se basa no solo en darle un lugar sino en darle una referencia que sustituya y simplifique el lugar. La memoria crea referencias, que contienen la estructura de la memoria. Ayudan a situarse, a darle una dirección. Las referencias se refieren a la memoria no a lo que ocurrió. Están separadas físicamente de la memoria. Son muy abstractas porque están altamente codificadas por reglas personales" 31 .

Probablemente es la obra desarrollada para la exposición Ida y vuelta sobre la ciudad de Cádiz: diagrama incompleto realizada en 2007 en la Caja San Fernando (Cádiz) la que ofrece el testimonio más transparente del complejo proceso creativo que conlleva realizar los signos de un diagrama, en este caso concreto el de una ciudad como Cádiz. En relación al trabajo realizado por Cadenas, el escritor Juan Bonilla afirmó: "el diagrama, el mapa, el ideograma, son artefactos milagrosos: aúnan la complejidad de lo expresado con la simplicidad o nitidez de la expresión"32.

\section{DIRECCIONES, MAPAS Y SÍMBOLOS}

Cadenas considera que la línea es el elemento esencial del dibujo y que su uso permite llevar a cabo un resumen de lo referido: "Lo específico de la gráfica es que es un recurso que explica mucho con muy poca construcción. Es algo que viene directamente del poder de la línea" ${ }^{33}$. El poder que posee la línea se hace patente en un buen número de sus obras en las que se observa el contraste que producen aquellos elementos dibujados de un modo aislado y nítido en contraposición con otras obras donde la yuxtaposición de iconografía puede incluso ofrecer una perspectiva laberíntica. En estas últimas la resolución gráfica de la

${ }^{31}$ LEO DE BLAS, Jana: El viaje sin distancia: Perversiones del tiempo, el espacio y el dinero ante el límite en la cultura contemporánea. Murcia, 2006, p. 116.

32 BONILLA, Juan: "Para un mural de Ricardo Cadenas", en Ida y vuelta sobre la ciudad de Cádiz, diagrama incompleto. Sevilla, 2007, p. 15.

${ }^{33}$ CADENAS, Ricardo: Procesos. El revés de la imagen. Sevilla, 2003, p. 26. 
línea, compleja por los estratos de imágenes sugeridos -como si se tratase de una versión creativa derivada del sistema de estratificación por planos de un sistema topográfico- se esgrime omnidireccionalmente como una trama ramificada por toda la superficie que requiere un viaje pausado de la mirada a través de ella. Paradójicamente, la mirada global a la obra dificulta en extremo un reconocimiento de las infinitas particularidades que se encuentran expresadas percibiéndose en una primera mirada como una naturaleza abstracta. Es precisamente una mirada pausada e indagadora la que logra que el elemento unitario se manifieste comprensible y evocador como un ítem que ofrece la llave que permite descubrir la existencia de las restantes. Es de este modo cuando pueden llegar a descubrirse las extraordinarias expresiones gráficas que se encuentran sugeridas en esa aparentemente falsa maraña de líneas. Esta propuesta estética se encuentra reflejada en algunas obras con abundantes yuxtaposiciones de dibujos de elementos vegetales e insectos como, por ejemplo, en Miguel Hernández (2008) y S/T (2008).

Se observa en la obra de Cadenas una reiteración en el empleo como recurso gráfico y conceptual de ciertas convenciones gráficas propias de la representación cartográfica. Es el caso de su interés por los mapas en general -y los mapamundi en particular-, los globos terráqueos, los callejeros de ciudades, las vistas aéreas, las cartas de navegación aéreas, los útiles para la orientación como, por ejemplo, astrolabios y rosas de los vientos. Estos elementos aparecen insertos en sus obras bien como recortes y fragmentos directamente extraídos de medios impresos o bien trazados habilidosamente a mano como un dibujo. Una revisión, en este sentido, de los recursos utilizados a lo largo de su trayectoria artística nos evidencia el interés que Cadenas siempre ha tenido por las distintas estrategias que sobre la interpretación gráfica del planeta Tierra han tenido lugar. El mapamundi no deja de ser un artificio que le fascina, una abstracción, que tiene su sentido en el dibujo que lo expresa. La reiteración en su obra de este elemento también se observa como una alegoría del descubrimiento y fascinación que produce la exploración del entorno, el viaje y la aventura. Un entorno común y global que se transforma en particular y único debido a la subjetividad, el recuerdo y la pasión de quien lo transita y lo da a conocer como una valoración estética que, por otra parte, no pretende imponerse ni mostrarse pretenciosamente definitiva. El globo terráqueo se observa como un contenedor inabarcable de acontecimientos. Un continente cuya comprensión, paradójicamente, requiere de un distanciamiento y abstracción que nos ayude a comprender mentalmente su estructura, disposición, tiempo, forma, lugar y modo en el que nos ubicamos en él. Se trata en definitiva de un ideograma que intenta dar respuesta a nuestra incapacidad de abarcar visualmente con total plenitud el lugar en el que vivimos. Las resoluciones gráficas para este posible diagrama se antojan múltiples. Cada una de ellas expresan una opción -una ficción-que evidencia el transcurso del tiempo como elemento transformador condicionante de la percepción que tenemos de nuestro universo. Por ello, el continente cartografiado nunca encierra una realidad -un 
estatus- inalterable. Porque el continente en el que vivimos, al igual que sucede con sus ciudades, y con quienes las habitan, es decir, con quienes tienen la capacidad de aportar su propio relato y perspectiva de ellas, no siempre son las mismas. En este sentido, la obra de Cadenas en relación a referencias como el viaje y la ciudad persigue recrear la fascinación producida por aquella primera vez que visitó un lugar o experimentó una vivencia. Y ese empeño por recuperar la fascinación de la emoción vivida lo lleva a cabo indistintamente bien a través de referencias cartográficas de carácter literal e inequívocas, bien con otras referencias más poéticas y evocadoras. Este proceder se encuentra en sintonía con la idea sugerida por Borges en su célebre texto Del rigor en la ciencia (1960) en el que nos advierte de que, a un mapa, por su mera condición como tal, no se le exige de una fidelidad representativa tan extrema que termine por hacerlo inútil. Precisamente su utilidad reside en su capacidad por expresar sintéticamente aquello significativo que permita puntualmente orientarnos, reconocernos o ayudarnos a tomar una decisión de recorrido del espacio. Cadenas propone este elemento desde una perspectiva conceptual relacionada con el espacio que representa el territorio artístico, su representación abstracta y carácter mnemotécnico.

Siendo un recurso habitual en la obra gráfica de Cadenas podríamos citar, a modo de referencia, algunos ejemplos en los que se incluyen mapas del globo terráqueo como se observa en la serie titulada Universal Melancholy (1988), S/T (Línea de cambio de fecha) (1991) y el cartel realizado para la XIX Bienal de Flamenco de Sevilla en 2016. Por su carácter alegórico también cabría reseñar Sin Título (1991) una obra en la que se incluye el texto "mapamundi".

Otra línea de trabajo que presentan sus obras hacen referencia al empleo como si de una trama pictórica se tratara- de mapas de ciudades, callejeros y también cartas de navegación aérea. En ocasiones, estos se encuentran impresos sobre papel vegetal y yuxtapuestos generando una amalgama enmarañada formada por líneas, gráficos y textos dificultosamente legibles ${ }^{34}$. En este grupo de obras podemos mencionar El pensamiento impreso (1994), S/T (1995), De entre

${ }^{34}$ En una de las entrevistas mantenidas, Cadenas nos revela que las cartas de navegación aéreas se las facilitaba un entrañable amigo, Carlos, que era piloto de Iberia. El artista sevillano deseaba las cartas de navegación que ya había utilizado en aquellos viajes transcontinentales porque le remitían a una experiencia del viaje vivida-auténtica-con el añadido de sus posibles anotaciones y tachones. Razón por la cual desdeñaba la posibilidad de que el material a utilizar en sus obras fueran cartas de navegación nuevas y sin uso. Estas cartas de navegación han formado parte de un buen número de obras. En ocasiones eran serigrafiadas directamente sobre el lienzo preparado -solían realizarlas en un taller de la calle Hortaleza de Madrid-; en otras ocasiones, se fotocopiaban sobre acetatos cuya superposición provocaban un efecto de trama. Estos elementos gráficos fueron utilizados en las obras que expuso con ocasión de su selección en 1991 en el prestigioso Salón de los 16, que por primera vez se realizaba en el Palacio de Velázquez, en el Retiro madrileño. Un ejemplo de estas obras lo representa $S / T$ (1991) (Figura 5). 
los muertos (1996), El Carbonerillo (1996) y This Side of Paradise (1994). También existe un particular interés conceptual por la ciudad: "A mí me gusta pensar en las ciudades como si fueran mapas subjetivos, una especie de diagramas en los que no se advierte una sola función, sino un entramado en el que se mezclan las imágenes; unas veces más definidas, otras casi imperceptibles, como sucede con la memoria" 35 .

Cabría reseñar la inserción en su obra de elementos iconográficos que también pueden funcionar como símbolos y que representan distintos medios de transporte que nos remiten al viaje y al tránsito de un gran espacio, sugiriendo rumbo y libertad de dirección de un recorrido. Para ello recurre a imágenes fotográficas, en ocasiones dibujadas, de barcos transatlánticos y aviones sobrevolando el cielo ${ }^{36}$ o desde el interior mismo de sus cabinas ${ }^{37}$. Tampoco faltan otras referencias gráficas del transporte por carretera como son los camiones y los coches, un claro símbolo de la libertad de movimientos no solo de la cultura americana. Un ejemplo muy poético es la imagen que representa un globo terráqueo en el que una cabalgata de camiones -como si de un anillo de Saturno se trataraforma un loop alrededor de él. Esta imagen es utilizada en varias ocasiones, por ejemplo en una obra como $S / T$ (La mirada falsa) (1996) a la que acompaña la silueta de un pinocho de nariz prominente. La referencia a estos medios de transporte, en definitiva de comunicación, se complementa con otras referencias a la comunicación que apuntan tanto a las máquinas complejas como a otros mecanismos de percepción sensorial del mundo circundante. Esto se observa con la utilización icónica del teléfono, pero también con la de otros dispositivos ópticos como son las prótesis oculares (Sobre la mirada, 1999) o la cámara fotográfica (Pintura al ojo para Picabia, 1998 y Sin Título, 2002). Otros elementos gráficos como astrolabios y rosas de los vientos subrayan el concepto poético de dirección múltiple y rumbo no fijado.

También mencionaríamos aquellas obras que presentan la imagen de la ciudad portuaria como origen -también destino- de la aventura (Visión nocturna de la Alameda Apodaca por el pintor Javier Buzón, 2007), y aquellas otras que nos hablan poéticamente de un espacio abierto y libre a través del mar y el viento como, por ejemplo, Viento de levante (2007), una obra que bien podría llevarnos en el recuerdo a aquellos primeros versos de Miguel Hernández: "Vientos del pueblo me

${ }^{35}$ CADENAS, Ricardo: Ida y vuelta sobre la ciudad de Cádiz: diagrama incompleto. Sevilla, 2007, p. 5.

${ }^{36}$ Refuerza esta idea el dibujo de vistas aéreas de ciudades en algunas obras como en Sin Título (1999) y Sin Título (Homenaje a Rimbaud), ambas de 1997 y ambas con referencia visual a la Île de la Cité de París, y Cádiz vista desde un aeroplano (2007).

37 Un ejemplo lo encontramos en $S / T$ (interior) (2005). 
llevan, vientos del pueblo me arrastran, me esparcen el corazón y me aventan la garganta" 38 .

Por último, el círculo -elemento gráfico repetido intermitentemente en sus obras- Cadenas lo relaciona simbólicamente con el universo guardando correspondencia con el estudio de Olivier Beigbeder, quien nos recuerda que "los compiladores de la época romana hacen del círculo el símbolo del universo y del hombre microcosmos, siguiendo en esto a la filosofía griega" 39 . Este se encuentra presente dominando el centro de la superficie de trabajo en obras como This Side of Paradise (1994), Aventuras en Oriente (2010) y Sin Título (2006). Otras obras presentan una composición muy particular al condensar los dibujos en una disposición circular. Es el ejemplo de Relojfloral I y S/T (Reloj Floral), ambas de 2006.

\section{CONCLUSIÓN}

A modo de conclusión señalaremos que este artículo responde a uno de los objetivos que motivaron nuestra investigación. Este objetivo no era el de descubrir al excelente artista que siempre ha sido Ricardo Cadenas sino, precisamente, reivindicar el valor y aportación que desde un aspecto concreto consideramos que desprende su obra y pensamiento como representa el de cartografía imaginaria. La aportación que ofrece nuestro estudio respecto a este creador ha sido la de generar una nueva lectura de su trabajo que indaga en todos aquellos elementos que, a lo largo del tiempo, se observan relacionados mostrándose coherentes y en discurso con el motivo principal de nuestro estudio. Consideramos que el abierto concepto de cartografía imaginaria es característico de su trabajo y que se encuentra presente en su obra como un leitmotiv.

En nuestro análisis se observa que Cadenas ha mantenido una actitud permanentemente proactiva hacia la práctica y reflexión en el arte contemporáneo y que ha explorado el territorio del dibujo y la pintura desde una percepción abierta, interdisciplinar e intelectual. En su obra se vislumbran conceptos como viaje, aventura, memoria, dirección, exploración de nuevos territorios, libertad de rumbo, tiempo, memoria, referencias gráficas como símbolos y otras alegorías autobiográficas de la imagen.

Se trata de un bagaje acumulado en años de creación artística en combinación con la docencia universitaria que nos permite interpretarlo como un particular cuaderno de bitácora. Su condición académica le hace ser consciente de la importancia en las Bellas Artes de transmitir el conocimiento en base a la propia experiencia.

\footnotetext{
${ }^{38}$ Versos pertenecientes al poema Vientos del pueblo me llevan, publicado en el periódico El mono azul, no 9, Madrid, el 22 de octubre de 1936.

39 BEIGBEDER, Olivier: Léxico de los símbolos. Madrid, 1989, p. 91.
} 
Su obra plástica también refleja esa voluntad por el compartir, por el hacer visible los entresijos que todo proceso de creación posee. De igual modo, también se encuentra el permitir al espectador la capacidad de reinterpretar la obra. Esto se plantea desde el beneficio de la sugerencia y el poder de reflexión que genera lo dibujado ${ }^{40}$.

Se observa tanto en su obra, como en los escritos que reflexionan sobre ella, la práctica creativa. También se vislumbra la acción del dibujo como un acto de fascinación ante la posibilidad de recuperar la emoción y el recuerdo vivido con esa misma intensidad.

Cadenas privilegia el valor de la práctica frente a la teoría si bien esta la cultiva a través de algunos escritos en los que reflexiona sobre los contextos y procesos creativos en los que él participa. Ambas, teoría y práctica, revelan el color del cristal con el que mira un artista cultivado a través del cual filtra sus múltiples lecturas y referencias tanto literarias, como poéticas, plásticas, musicales, etc. También se observa el valor fundamental que otorga al tiempo de conversación y diálogo que mantiene con amigos artistas sobre temas variados del arte. Una práctica muy común en su estudio del barrio de Triana, por ejemplo.

Su obra y pensamiento refleja el permanente interés por la reflexión y crítica en torno a la imagen pública y sus lenguajes, igualando el del cómic a la de cualquier categoría artística. La estructura compositiva de un buen número de sus obras, su dimensión conceptual, el uso de imágenes fragmentadas, temáticamente dispersas y en elevada cantidad, así como la consideración que otorga a símbolos e iconos a modo de índices o direcciones, nos permiten interpretarlas como complejas cartografías de la memoria.

Consideramos la obra realizada en 2007 para la exposición titulada Ida y vuelta sobre la ciudad de Cádiz: diagrama incompleto, la más representativa de su trayectoria creativa en el contexto de la cartografía imaginaria que hemos abordado.

Los símbolos y conceptos se reiteran en el tiempo a lo largo de su obra y de su discurso estético. Estos se manifiestan intermitentemente bien a nivel metafórico o literal. Estas iconografías nos remiten a los diagramas, al mapamundi, a los mapas, al espacio, al tiempo, a la memoria, a los habitantes de su memoria-ficticios o no-, a la presencia de la muerte como algo consustancial a la vida y, en relación a esta última, a su expresión en múltiples manifestaciones. Esta sinergia termina por crear un mundo personal imaginario que se encuentra explorado y vivido como un espacio mental. El valor de Ricardo Cadenas es que consigue materializarlo gráficamente en exquisitos retazos con el objeto de brindárnoslo a nuestra propia indagación.

Fecha de recepción: 28 de septiembre de 2016

Fecha de aceptación: 4 de enero de 2017

${ }^{40}$ Por su carácter didáctico, aportamos la dirección web de su página oficial en la que próximamente estará disponible abundante documentación gráfica y textual: http://www. ricardocadenas.es. 


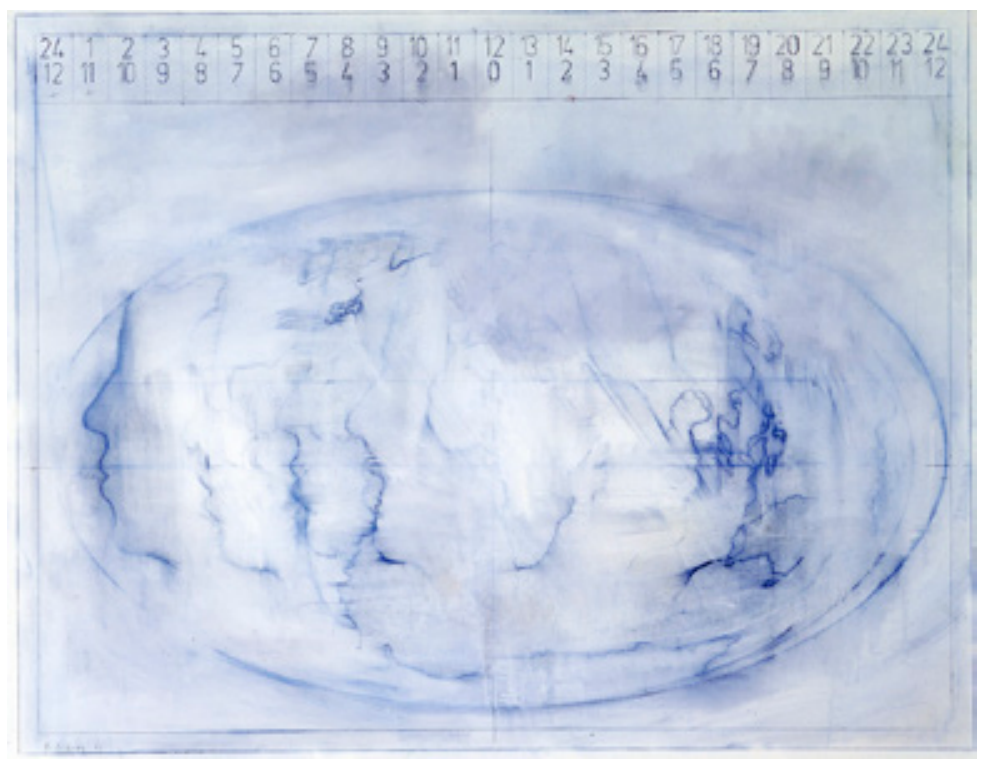

Figura 1. Ricardo Cadenas, S/T (Línea de Cambio de Fecha), 1991, técnica mixta sobre lienzo, 114 x $146 \mathrm{~cm}$.

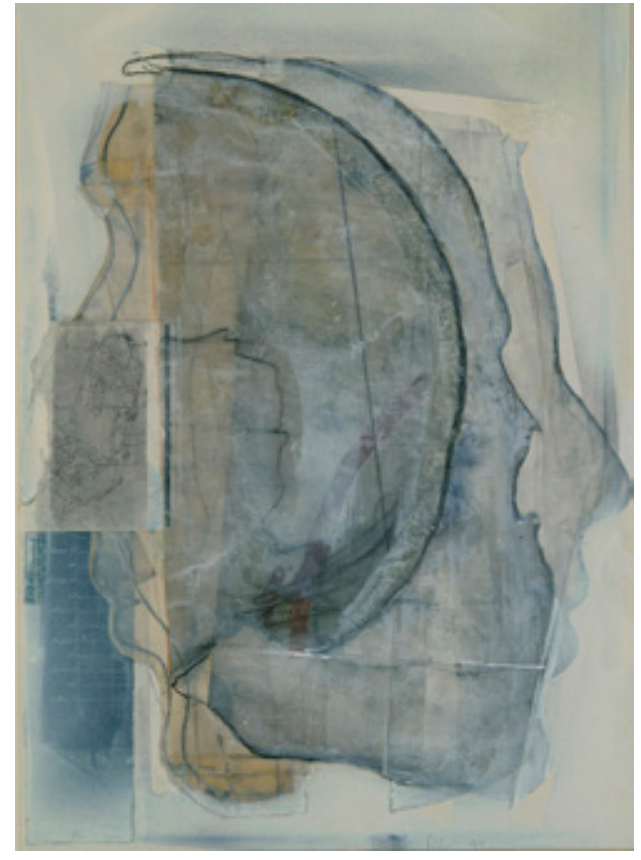

Figura 2. Ricardo Cadenas, Perfil, 1993, técnica mixta sobre cartón, 70 x $50 \mathrm{~cm}$. 


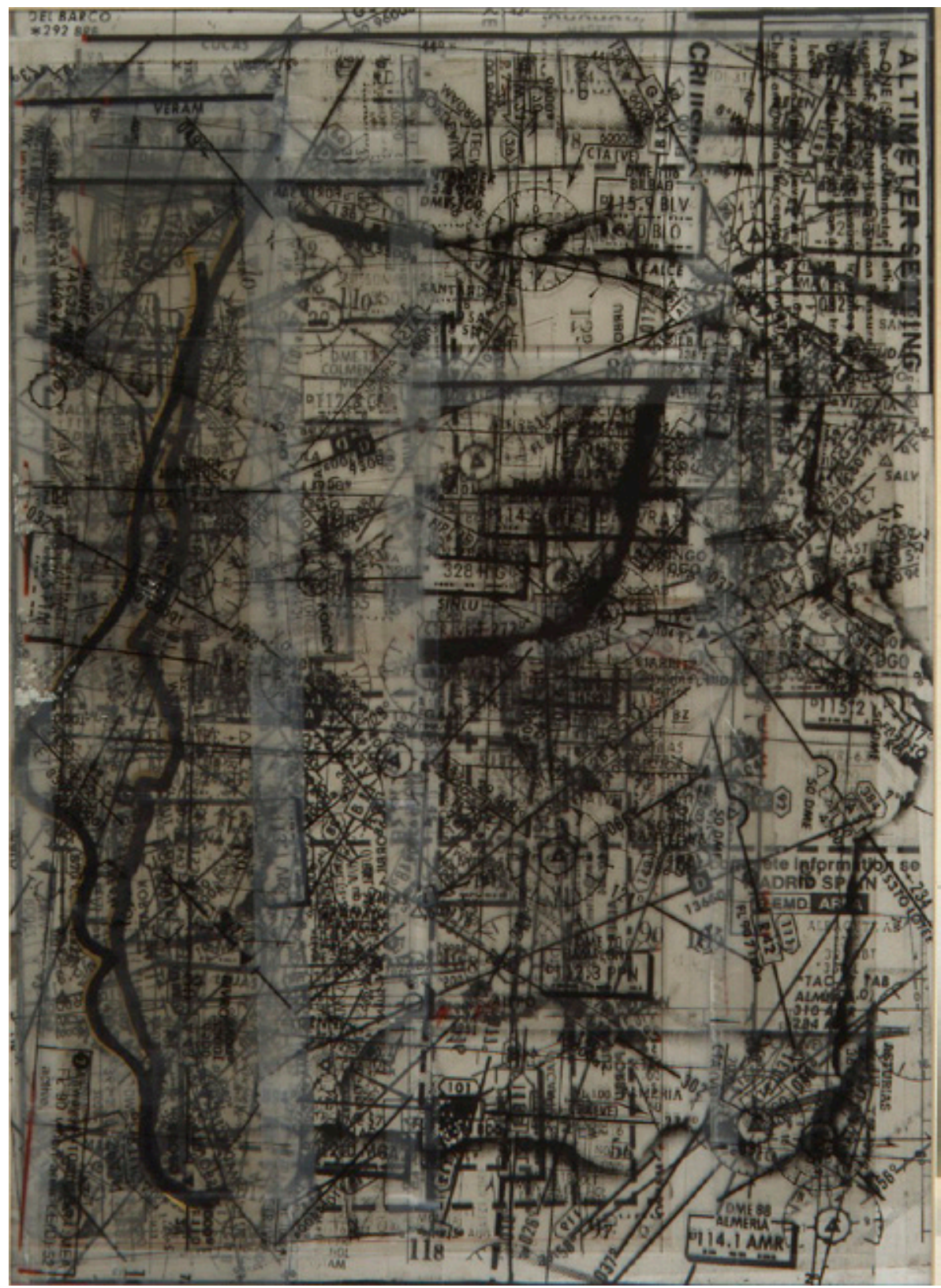

Figura 3. Ricardo Cadenas, Perfil I, 1993, técnica mixta sobre cartón, 70 x $50 \mathrm{~cm}$. 


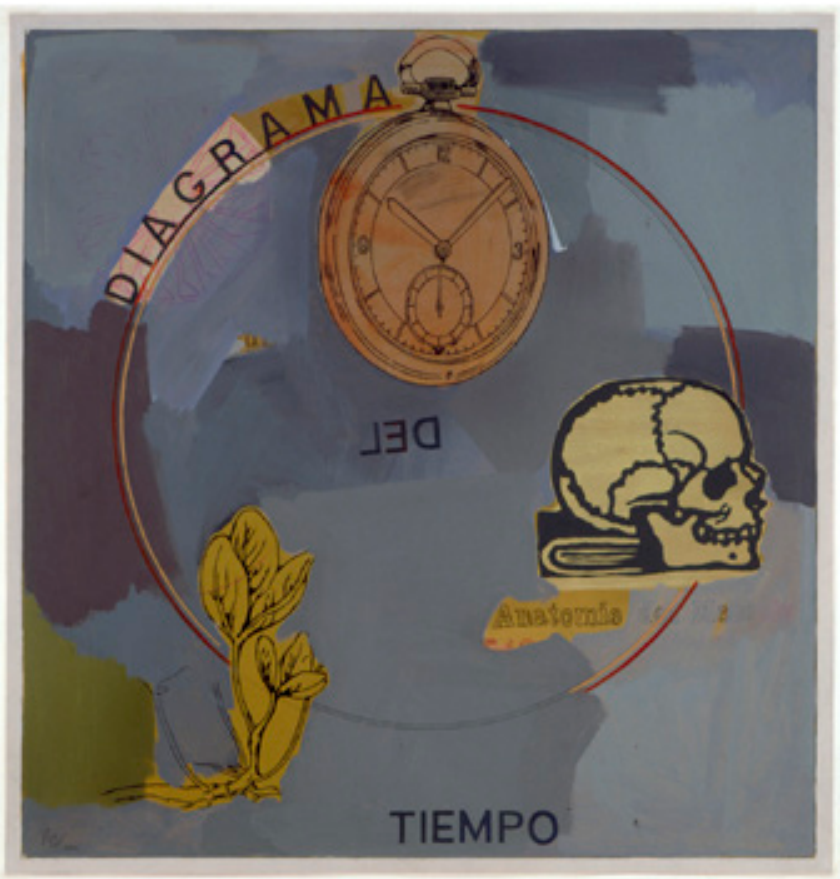

Figura 4. Ricardo Cadenas, Sin Título (Diagrama del Tiempo), 2002, técnica mixta sobre cartón, 70 x $50 \mathrm{~cm}$.

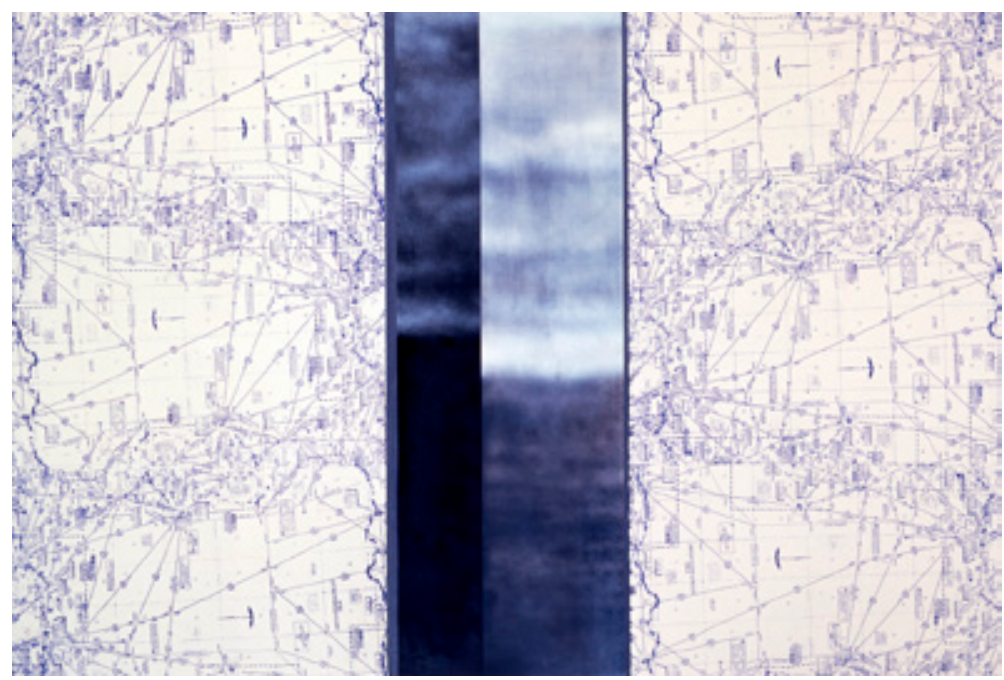

Figura 5. Ricardo Cadenas, $S / T, 1991$, técnica mixta sobre lienzo, $162 \times 260 \mathrm{~cm}$.

LABORATORIO DE ARTE 29 (2017), pp. 755-776, ISSN 1130-5762

e-ISSN 2253-8305 - DOI http://dx.doi.org/10.12795/LA.2017.i29.41 